\title{
OFF - O MAL (DES)NECESSÁRIO: A PRODUÇÃO DE REPORTAGENS SEM LOCUÇÃO
}

\author{
Sandra Nodari ${ }^{1}$
}

\begin{abstract}
Resumo
Analisar a ausência de um narrador oficial na reportagem é a questão principal desse trabalho. Para tanto é preciso investigar a ingerência da locução sobre as imagens na reportagem de telejornalismo questionando a prisão ao formato pré-determinado baseado em off+passagem+sonora. Discutir a relação entre off e imagem é questionar a forma de comunicação presente nos elementos visuais cotidianos. Dessa forma, é possível verificar a ingerência do repórter na reportagem e buscar uma forma de produção de reportagem em que não haja narração como elemento principal de comunicação. Esta análise é um estudo de caso de reportagens produzidas por alunos do curso de Jornalismo da Universidade Positivo. Palavras-chave: Telejornalismo, reportagem, off, experimentação.
\end{abstract}

\begin{abstract}
The main goal of this study is to analyze the absence of official narrators in some TV reports. In order to do so, we investigate the off-screen voice's interference with images in TV reports by questioning the limitation caused by the use of old TV formulas. To discuss the relation between off-screen voice and the images means to question the communication forms present in everyday visual elements. Thus, it is possible to verify the reporter's interference on TV reports and to seek a form of production in which narration is not the main element of communication. This analysis is a case study of TV reports produced by students in Journalism at Universidade Positivo.
\end{abstract}

Keywords: TV journalism, report, off-camera voice, experimentation.

\section{Introdução}

Este trabalho pretende discutir a estrutura narrativa verbal e imagética utilizada na reportagem de telejornalismo, dando ênfase à presença e à ausência de um narrador oficial com voz em off e das vozes dos outros personagens. Compreende-se por off a voz do repórter ou apresentador de telejornalismo falando sem aparecer no vídeo, é a narração corrente do texto jornalístico. Trata-se de parte integrante da reportagem de televisão cujo padrão de realização é formado por off+passagem+sonora. Considerando o off como a locução, a passagem é a imagem do repórter olhando para a câmera e falando uma parte da notícia e a sonora é a entrevista ou o depoimento do personagem da reportagem. Como este formato contempla a maioria das reportagens exibidas em televisão e nesta contemporaneidade a TV busca formas de se reinventar e testar novos formatos, as reportagens sem off podem apresentar-se como alternativa a ser testada principalmente nas faculdades de Jornalismo.

\footnotetext{
${ }^{1}$ Jornalista e professora do Curso de Jornalismo da Universidade Positivo, mestre em Comunicação e Linguagens pela Universidade Tuiuti do Paraná (UTP). E-mail: sandranodari@up.com.
} 
Produzir e editar uma reportagem sem off tem sido uma das atividades obrigatórias dentro da disciplina de telejornalismo II, do curso de Jornalismo da Universidade Positivo, nos últimos quatro anos. Quando a atividade é apresentada aos estudantes, a primeira reação é a de surpresa: "Como realizar uma reportagem sem off?". Depois da conceituação e de assistir a exemplos já produzidos, inclusive aqueles premiados em concursos, os alunos aceitam o desafio e seguem adiante. Neste artigo, vamos mostrar um pouco desta experiência.

\title{
O off nas reportagens de televisão
}

Para iniciar esta discussão faz-se necessário primeiro compreender a expressão Off a partir de autores que trabalham com este conceito. Segundo Ismail Xavier,

\begin{abstract}
No Brasil, como na França, usa-se em geral a expressão voz-off para toda e qualquer situação em que a fonte emissora da fala não é visível no momento em que a ouvimos. Nos Estados Unidos, há uma distinção entre: (1) voz-off, usada especificamente para a voz de uma personagem de ficção que fala sem ser vista mas está presente no espaço da cena; (2) voz-over, usada para aquela situação onde existe uma descontinuidade entre o espaço da imagem e o espaço de onde emana a voz, como acontece, por exemplo, na narração de muitos documentários (voz autoral que fala do estúdio) ou mesmo em filme de ficção quando a imagem corresponde a um flashback, ou outra situação, onde a voz de quem fala vem de um espaço que não corresponde ao da cena imediatamente vista (XAVIER, 1983, p. 459).
\end{abstract}

Neste trabalho usaremos a expressão voz off para a locução de telejornalismo e voz fora de campo para o que Ismail chama de voz over, da mesma forma que o faz Bernardet para filmes documentários:

\begin{abstract}
Chamo de "locutor" ou "voz off" a voz que lê o "comentário" ou "narração" do filme, e somente essa. Conservo a expressão "voz off" por ser usual em português, apesar de imprecisa, pois são off todos os sons cuja fonte não é visível na imagem (afirmação também imprecisa). A voz de um ator que deixa o campo (espaço visível na imagem), mas continua falando torna-se off. A expressão norte-americana "voz over" para designar a voz da "narração" é mais precisa, mas não a emprego por não ser de uso corrente (BERNARDET, 2003, p. 297).
\end{abstract}

As reportagens de televisão têm como elementos principais: imagem e voz. Sendo que a primeira parece ter a função de ilustrar ou confirmar o que é contado pelo repórter na narração, usando da redundância. Da mesma forma, os depoimentos servem para ratificar o que é dito pelo jornalista, que por meio da voz off tem controle sobre a narrativa, inclusive o de interpretar os dados e relatá-los ao público.

Os manuais de telejornalismo destacam a relação entre imagem e palavra: "É preciso respeitar a força da informação visual e descobrir como associá-la à palavra, porque a 
informação na TV funciona a partir da relação texto/imagem" (PATERNOSTRO, 1999, p. 61). Ainda: "É o texto que vai contar ao telespectador o que ele está vendo na tela da TV. O termo off é usado porque o repórter não está mais em cena, é a voz dele que cobre as imagens, narrando (contando) os acontecimentos. O off compõe a maior parte da matéria de TV" (VILELLA, 2008, p. 24). A relação entre imagem e palavra é destacada também da seguinte forma: "Não use na reportagem mais palavras do que a duração das imagens permite, nem escreva sem prestar atenção ao conteúdo das imagens. Não redija frases que expliquem exatamente o que as imagens estão mostrando" (BARBEIRO, 2002, p. 69). Sobretudo porque "Não adianta levantar uma série de informações se não há como cobrir os offs, o texto narrado pelo repórter é ilustrado com imagens" (CARVALHO, 2010, p. 37).

Muitas vezes, quando o telespectador assiste a uma reportagem, sente como se já a tivesse visto em outro canal ou momento. Se for levado em consideração, por exemplo, que uma matéria sobre o dia das mães é exibida a cada ano de maneira muito parecida, a impressão que pode causar ao telespectador é de repetição, cópia ou reprodução. O mesmo acontece em quase todas as coberturas factuais que se repetem ano a ano, resultando em reportagens e telejornais muito parecidos.

A mesma situação é apontada em outros produtos audiovisuais que se utilizam de off como ferramenta para contar histórias, como é o caso do documentário, principalmente aquele exibido em emissoras de televisão, o que acarreta comparação com a reportagem.

De tal modo defendeu esta posição que o documentário ficou conhecido como um filme de intervenção social onde predomina a voz off. Este padrão foi adoptado como standard e de tal modo foi que em muitos países, incluindo Portugal, o filme documentário é associado a apenas este tipo de filme (e o uso da voz off é uma das razões porque é vulgarmente confundido com reportagem) (PENAFRIA, 1999).

Este padrão que tem o off como principal ferramenta tem feito parte da história do audiovisual informativo.

Assim que o cinema se tornou sonoro, instituiu-se no documentário inglês, já no início dos anos 30, a voz em off, que narra, a voz de Deus desencarnada e não sincrônica em relação à imagem. Essa voz interpreta o que vemos nas imagens e fornece ao espectador o significado unívoco do filme (LINS, 2004, p. 69).

No Brasil, na década de 1970, o documentarista Eduardo Coutinho, iniciou a experiência de retirar o off dos documentários que dirigiu para o Globo Repórter. 
Já nos anos 1970, o documentário Teodorico, o Imperador do Sertão obtivera uma vitória rara no formato do Globo Repórter, que foi a supressão da narração onisciente a cargo de um locutor da casa. Notam-se, na obra futura de Coutinho, a progressiva retirada do off e a concentração da dramaturgia da fala (MATTOS, 2003, p. 12).

Esta experiência de Coutinho pode levar a uma constatação: se nas reportagens é certo observar-se a repetição constante dos formatos, no documentário isso se torna menos comum, há maior possibilidade de buscar e testar novas possibilidades audiovisuais, como confirma Penafria. "No documentário a relação conteúdo-forma deve ser constantemente criada [...] para cada conteúdo e cada ponto de vista a ele relativo existe uma forma que deve ser encontrada e que o documentarista acede pela criatividade" (PENAFRIA, 1999, p. 63).

O documentário pode encontrar caminhos estéticos que o telejornalismo não permite, principalmente devido ao engessamento imposto pelo padrão off-passagem-sonora. Ao adotar a palavra como instrumento de transmissão de significados, segundo a teoria de Mikhail Bakhtin, o entrecruzamento de vozes pode permitir uma análise com relação à transmissão de mensagens pictóricas e emocionais ou de nenhuma mensagem. Embora documentário e telejornalismo nunca tenham sido tratados diretamente por Bakhtin, Robert Stam faz uma analogia entre estes temas e a obra do teórico. Stam aborda o "tato" existente no diálogo metafísico envolvendo filme e espectadores devido à contextualização visual e auditiva do discurso. Trata do que Bakhtin chama de entonação, por meio da qual o sujeito falante estabelece o contato com o seu ouvinte. "Não é difícil analisar documentários em termos de ‘tato' e 'entonação', a maneira como representam valores culturais e posições políticas”, (STAM, 2000, p. 63). Ele classifica os locutores como "adultos discursivos” em oposição aos personagens que seriam "gaguejantes e infantilizados".

[...] os noticiários de televisão também apresentam seu próprio "tato" específico. Uma elaborada hierarquia de artistas da fala que inclui desde os locutores do topo, até os correspondentes e repórteres, como atores coadjuvantes, trata condescendentemente os "figurantes", as pessoas da rua (p. 64).

Arlindo Machado trata de dois modelos de telejornalismo: os polifônicos e os opinativos. Para ele, opinativos são aqueles em que o âncora "tem poderes de decidir sobre as vozes que entram e saem" (2000, p. 108), determinando e tendo a última palavra sobre tudo o que for exibido no telejornal, sobre todos os textos e falas. Já polifônicos são aqueles em que as pessoas que compõem a equipe do telejornal, como redatores, repórteres, editores, têm participação nos textos lidos pelo apresentador. Além disso, a opinião fica a caráter do entrevistado e não dos jornalistas. Embora considere polifônico, o telejornalismo em que várias 
pessoas compõem vários textos, cada texto acaba sendo finalizado por uma única pessoa, que parece manter um caráter autoritário quando traduz nas próprias palavras o que muitas outras dizem, como é o caso do repórter.

Se o documentário e o telejornalismo influenciam-se mutuamente desde a invenção da televisão, a questão a ser discutida é: por que o primeiro desenvolve linguagens próprias, criativas, experimentais, enquanto a segunda mantém-se engessada num padrão que faz do off o principal meio de se contar uma história?

\title{
Reportagens sem off
}

A alternativa de produzir reportagens sem o recurso da locução é uma forma de permitir experimentação de linguagem. Em vez de basear-se no padrão off+passagem+sonora, a matéria conta com entrevistas+sons+imagens para contar a notícia. Esta linguagem, usual no documentário, requer do repórter e do editor um tempo maior para a produção, decupagem e criação de um roteiro de edição. Este processo leva mais tempo que o de uma reportagem com off, talvez este seja um dos motivos pelos quais programas que não trabalham com notícias factuais, mas com assuntos mais frios, consigam utilizá-lo, enquanto os telejornais, não consigam investir este tempo. Porém, se formos avaliar a produção de reportagens especiais produzidas pelos telejornais, é possível entender que são matérias mais elaboradas e que permitem mais tempo para serem realizadas, independentemente do modelo que sigam. Para Siqueira:

\begin{abstract}
A escolha do formato tem a ver com vários fatores, entre eles: com os recursos disponíveis, o acesso às fontes, a apuração dos fatos, a disponibilidade de imagens e entrevistas. [...] É importante ressaltar ainda que essa opção por um modelo em detrimento de outro possui relação também com o modo de fazer Jornalismo, que, na atualidade, está mais próximo dos cidadãos, no sentido de que estes participam mais ativamente dos meios de comunicação, na coprodução de imagens por exemplo (2012, p. 187).
\end{abstract}

As reportagens sem off poderiam ser produzidas como alternativa de linguagem para matérias especiais. Talvez não o sejam por falta de conhecimento e de interesse em testar um modelo diferente do usual. Para Lima, as reportagens especiais têm a função de ampliar os fatos; possibilitar a compreensão de maior alcance; permitir a dimensão contextual em vez do relato raso. O autor explica que tal matéria: “[...] possibilita um mergulho de fôlego nos fatos e em seu contexto, oferecendo, a seu autor ou a seus autores, uma dose ponderável de liberdade para escapar aos grilhões normalmente impostos pela fórmula convencional do tratamento da notícia, com o lead e as pirâmides (LIMA, 2004, p. 18). Desta forma, podemos pensar na 
matéria especial dando liberdade ao jornalista de escolher uma forma diferente de editar seu material bruto.

No Telejornal-laboratório diário Tela $\mathrm{Un}^{2}$ do curso de Jornalismo da Universidade Positivo este tipo de reportagem é produzido com alunos que já praticaram o formato padrão off+passagem+sonora e devem experimentar novas opções. Ao assumir o desafio de testar esta linguagem, o aluno percebe que é necessário dedicar mais tempo à produção, uma vez que as informações serão transmitidas pela fala dos entrevistados, estes devem ser bem escolhidos. Descobrem, também, que além de gravar sonoras mais longas, as falas precisam ter começo, meio e fim. Então, há a necessidade de fazer perguntas cujas respostas sejam completas. Caso contrário, na hora de editar, ficará difícil juntar falas.

Se a produção leva mais tempo, a edição também consumirá mais horas. Primeiro, porque as sonoras têm de ser assistidas e decupadas na totalidade, depois, porque há necessidade de se produzir um relatório que apresente detalhadamente os elementos a serem usados na composição da reportagem que poderá contar com trilha sonora, abre áudio, som ambiente, telas, letreiros e outros elementos que compõem a linguagem de edição.

Na reportagem que ganhou o nome de "Costurista" (junção das palavras costureira e artista), a estudante de Jornalismo Priscila Pacheco, então no $3^{\circ}$ ano do curso, contou a história de Lisa Simpson, uma curitibana que trabalha com criação e customização de roupas usadas, com o objetivo de propor a reciclagem como alternativa para a moda atual. Além de customizar roupas, a artista faz música com a máquina de costura. As imagens foram produzidas pela aluna individualmente, usando de vários ângulos, enquadramentos e movimentos de câmera, para retratar o atelier da personagem. A produção foi realizada em duas etapas, num primeiro momento filmando o trabalho da artista e num segundo uma apresentação da mesma acompanhada de voz e vilão pela musicista Vilma Ribeiro. Ao formato imagens+entrevista+imagens, a estudante utilizou além de trilha sonora, o som ambiente da máquina de costura, as falas da costurista no atendimento às clientes, os acordes do violão e da voz da cantora. A estrura de informação seguiu o formato: personagem+informação+personagem.

A reportagem abre com trilha sonora alegre, cobrindo imagens externas do atelier, closes na frase "Recicle suas roupas" (adesivada no vidro da loja) e das palavras"Agente" e "Costura”, além de rostos, impressos na parede. Em seguida há imagens internas do local: fios,

2 O Telejornal-laboratório Tela Un é produzido diariamente, de segunda a sexta-feira por alunos do curso de Jornalismo da Universidade Positivo durante o período letivo. O telejornal é exibido no canal: youtube.com/telaun1. 
agulhas, tesouras, mãos operando a máquina de costura (neste momento o áudio da trilha é baixado e há a entrada do áudio ambiente da máquina). Ao baixar o som, entra a personagem em plano médio, sentada, olhando para a câmera e dizendo: "Meu nome é Lisa Simpsom. Eu sou costurista, formada em artes visuais e amante da costura". Em seguida há um trecho de 6 segundos de imagens e áudio ambiente da personagem costurando. Na sequência, a personagem em quadro explica: "Agente Costura é uma alternativa para todas as peças que você tem guardadas no seu guarda-roupa, que você não tá usando, que você não consegue se desfazer, e a gente tenta dar uma nova cara paras as velhas roupas".

Em seguida, há um insert de 2 segundos de imagens da artista atendendo uma cliente para seguir a explicação: “A gente quer mesmo reciclar, botar em uso, as coisas que estão ali paradas, e também garimpar as peças mais antigas, que têm tecidos que eram feitos para durar, acabamento era uma coisa que existia há vinte anos atrás. Hoje em dia é tudo muito descartável". Este último trecho é coberto com imagens do atelier, de várias clientes olhando roupas nas araras e sendo atendidas por Lisa. A seguir, há mais um trecho de entrevista também coberta com imagens do trabalho da moça, de manequins e peças de roupa: "Bom, eu estou sempre procurando referências, tiro muito da história da arte. E também coisas da atualidade, filmes, revistas". Neste trecho, a personagem volta a ficar em quadro para dizer: "Passear pelo mundo: adoro viajar. Acho bem importante trazer coisas de fora e levar coisas daqui para lá e ver o quanto são relevantes no resto do mundo. E cada peça tem uma história. Sempre que vem alguém com uma encomenda, eu levo em consideração a pessoa que é dona da roupa e a roupa em si." Esta última frase é coberta com a imagem de uma cliente experimentando um vestido e conversando com a costurista sobre os ajustes a serem feitos na peça de roupa. Este diálogo fica audível na edição.

$\mathrm{Na}$ metade da reportagem quando a personagem explica como é a aceitação do seu trabalho, há uma inserção de imagens em stop motion cobrindo sua fala. São fotos de Lisa costurando uma peça de roupa, usando a máquina de costura, cobertas com a trilha que é usada desde o início da matéria. Quando a personagem fala de sua nova empreitada - fazer música com o som da máquina de costura - a trilha sonora muda: agora ouvimos como som ambiente a música interpretada por Vilma Ribeiro, que aparece no vídeo tocando violão e cantando. As duas personagens dividem a tela, Lisa está costurando à máquina (que está microfonada) e cujo som acompanha o ritmo do violão. Dos 3'10"' até o final da reportagem assistimos a um plano sequência, com câmera na mão, da execução de uma música pelas duas artistas. A reportagem 
com duração de 3'52" foi exibida no canal do Tela Un no youtube em julho de $2012^{3}$ e venceu dois concursos: Projeto em Telejornalismo, do prêmio Sangue Novo no Jornalismo Paranaense, em 2012, e foi escolhida na Seleção Oficial no Festival de Cinema Visões Periféricas, Rio de Janeiro, 2011.

Outro exemplo de destaque entre as reportagens produzidas sem off pelos alunos é a história de um carrinheiro que adotou um cachorro vira-latas para viver com ele numa praça em Curitiba. A equipe formada pelas alunas Jaqueline Baumel, Jucélia Chiquim e Kathulin Tanan, também do $3^{\circ}$ ano, iniciou a produção da reportagem sobre Bocão (pessoa em situação de rua) e Polaco (o vira-lata) para fazer parte de uma série especial sobre relacionamentos entre homens e animais. As imagens e a entrevista com Bocão foram produzidas no final de 2013, mas não chegaram a ser editadas naquele ano. Em janeiro de 2014, o carrinheiro foi assassinado e a notícia mobilizou a cidade (GAZETA DO POVO, 2014).

Utilizando o material já captado, no primeiro bimestre de 2014, a equipe reiniciou a produção da reportagem, com entrevistas de pessoas que conheciam Bocão e que contaram a história dele, além de especialistas. Com entrevistas, trilha sonora, telas, imagens dos jornais impressos que relataram a morte de Bocão foram usados para fechar o VT.

A reportagem inicia com 10" de imagens de Bocão interagindo com Polaco, brincando com o cão, tirando o óculos solar do rosto e colocando no cachorro, sob uma trilha sonora calma. Em seguida entra o personagem em plano médio falando: "Eu vou falar pra você uma coisa: esse cachorro é a minha vida. Ele pra mim é tudo." Mais 5 segundos de imagens dos dois interagindo, em seguida cobertas com a voz de outro entrevistado: "O Bocão era muito conhecido ali na praça em função de um cachorro, de um vira-latas que ele tinha, que tratava com muito carinho, com muito amor". Mauro Welter, jornalista, é creditado quando sua imagem entra em quadro. "Eles eram muito conhecidos na praça justamente por que eram grandes parceiros. O Polaco que era o cachorro, cuidava de certa forma do Bocão durante a madrugada". A música, que não é cortada durante as entrevistas, segue com novo clipe de imagens de Bocão colocando um chapéu no cachorro. Em seguida, aparece dizendo: "Eu pedi para Deus este cachorro. Umas pessoas falaram pra mim que ele é meu anjo.” Esta frase é coberta com imagens dos dois, seguida de mais um trecho com música.

Outro personagem aparece falando, então, em quadro: "Esse carinho do animal. Esse amor incondicional, em especial do cachorro, é algo que faz muito bem ao ser humano", e

\footnotetext{
${ }^{3}$ Endereços para assistir a Costurista: https://www.youtube.com/watch?v=h-QNnaAFnZQ e http://vimeo.com/50891620
} 
recebe o crédito Tonio Luna, psicólogo. Volta ao quadro o jornalista dizendo que: "A relação que ele tinha com este cachorro era uma relação de amizade pura, de um cuidar do outro, eram grandes parceiros. Eu presenciei um fato curioso envolvendo os dois. Era noite, o Bocão já estava dormindo embaixo do carrinho que ele catava papelão e Polaco era o cão de guarda que ficava ali. Eu presenciei um estranho se aproximar e o Polaco avançar no estranho defendendo o Bocão". Um trecho desta fala é coberta com imagens do cachorro deitado sob o carrinho.

A matéria conta, além do psicólogo, com outra especialista: "Então o cão tem sim afeto. Ele sente emoções positivas em relação a pessoas, ou negativas" - neste trecho a tela é divida entre a imagem da médica veterinária comportamentalista Larissa Rüncos, em quadro e a do cão deitado no chão - "ele forma vínculos afetivos, vínculos de amizade. Então, ele gosta”, explica. Tanto ela como o psicólogo vão explicar a relação entre animal e ser humano e sobre o relacionamento do morador de rua com animais.

Ao final da reportagem, a trilha sonora muda para um som mais melódico e a tela escurece. Uma imagem de um jornal impresso, cuja reportagem traz o título "Morre carrinheiro agredido na Praça Santos Andrade", divide a tela com um texto informando sobre a morte de Bocão. A última frase informa o que aconteceu com o cão: "Polaco foi adotado por outros moradores de rua, que vivem na praça Santos Andrade”. Imagens em preto e branco de Bocão e Polaco aparecem na tela sob a voz do jornalista dizendo: "Nesta madrugada, que ele faleceu, não sei exatamente o que aconteceu que Polaco não estava, não conseguiu para defender o fiel amigo dele que era o Bocão", encerra a matéria.

Além de ser exibida no canal do Tela Un, em 25 de abril deste ano, a reportagem ${ }^{4}$ de 3'47' foi transmitida também, sem cortes, pela Rede Massa, emissora de Curitiba afiliada ao SBT, no dia 26 de junho, cedida à emissora. Para a equipe, ter sua reportagem exibida num programa noticioso, veiculado para todo o Estado do Paraná, foi como um prêmio de reconhecimento de qualidade. $\mathrm{O}$ fato de uma emissora comercial ter exibido a reportagem realizada por estudantes, pode indicar que os telejornais também buscam novos formatos, mas talvez tenham dificuldade em praticá-los porque a rotina diária não permite tempo para experimentação.

\section{Considerações finais}

As duas reportagens analisadas, embora sem off, contam informações fundamentais para a compreensão da notícia e vão além delas, permitindo a ampliação do conhecimento sobre os

\footnotetext{
${ }^{4}$ Endereço para assistir à reportagem sobre Polaco e Bocão: https://www.youtube.com/watch?v=mxdSCWMGZ34
} 
assuntos retratados, cumprindo a função das matérias especiais como defende Lima: "É a ampliação do relato simples, raso, para uma dimensão contextual” (2004, p. 18). É possível compreender que este estilo de reportagem especial pode ser aplicado tanto a assuntos mais leves quanto a mais sérios. "A diferença é que uma reportagem especial pode conter conceitos, comentários e opiniões que possibilitam ao autor explorar as questões levantadas pela notícia de forma mais criativa (RUDIN, 2008, p. 58). Ainda assim, a reportagem deve seguir convenções estipuladas na produção da notícia: "Em geral, reportagens de entretenimento não seguem a fórmula das notícias factuais, mas devem ter início, meio e fim que conduzam a um fluxo lógico de informações, comentários, ilustrações e referências, mantendo assim o interesse do leitor (p. 58).

As reportagens sem off traduzem o que defende Carvalho quando explica que o que torna uma reportagem especial: "é o tratamento muito mais primoroso, tanto de conteúdo quanto plástico. Ela nos permite aprofundar assuntos de interesse público, que podem ser retratados em uma única reportagem ou em uma série” (2012, p. 21).

Mas nem todas as reportagens realizadas pelos alunos são completas de informações e ricas em sons+imagens como nos exemplos citados. Muitas das experimentações dos estudantes transformam as possíveis reportagens em meras entrevistas editadas. Este resultado aparece no momento de pensar a edição, quando o aluno não organizou um roteiro de gravação, e tem poucos elementos para compor a reportagem. Ele apenas troca o off do repórter pelo off (ou a voz fora de campo) do entrevistado ou por trechos editados da entrevista.

Outro erro comum é confundir reportagem grande com grande reportagem uma vez que a matéira especial é maior que a factual: "Ela ganha, sim, segundos ou mesmo minutos a mais em relação às notícias do dia. E usa algumas ferramentas presentes nos documentários. Mas não é o tempo ou os meios que a definem" (idem).

A partir das experiências realizadas em sala é claro definir que há a necessidade de praticar na Universidade novos formatos de produção de reportagens de telejornalismo, não só pela facilidade com que os alunos têm de experimentar novas tecnologias, mas pela disponigilidade de tempo e independência quanto ao deadline, diferentemente das emissoras. De qualquer forma, a experiência de tentar fugir do padrão é algo que enriquece a formação do estudante de jornalismo e permite a criação de novas alternativas ao telejornalismo. (Artigo recebido em 30/10/2014, aprovado em 21/11/2014)

\section{Referências}

BARBEIRO, Heródoto. Manual de telejornalismo. Rio de Janeiro: Campus, 2002. 
BERNARDET, Jean-Claude. Cineastas e imagens do povo. São Paulo: Brasiliense, 1992.

Gazeta

do

Povo,

2014.

http://www.gazetadopovo.com.br/vidaecidadania/conteudo.phtml?id=1446867. Acesso em 14 de julho de 2014.

Bocão $e$ Polaco. A reportagem. Disponível em: $>$ https://www.youtube.com/watch?v=mxdSCWMGZ34<. Acesso em 14 de julho de 2014.

Costurista. A reportagem. Disponível em: >https://www.youtube.com/watch?v=hQNnaAFnZQ

e http://vimeo.com/50891620<. Acesso em 14 de julho de 2014.

CARVALHO, Alexandre (Org.). Reportagem na TV: como fazer, como produzir como editar. São Paulo: Contexto, 2010.

DA-RIN, Silvio. Espelho Partido: tradição e transformação do documentário. Rio de Janeiro: Azougue Editorial, 2004.

LIMA, Edvaldo Pereira. Páginas ampliadas: o livro-reportagem como extensão do jornalismo e da literatura. Barueri: Manole, 2004.

LINS, Consuelo. O documentário de Eduardo Coutinho: televisão, cinema e vídeo. Rio de Janeiro: Jorge Zahar, 2004.

MACHADO, Arlindo. A televisão levada a sério. São Paulo: Senac, 2000.

MATTOS, Carlos Alberto. Eduardo Coutinho: o homem que caiu na real. Santa Maria da Feira (Portugal): Cineclube da Feira, 2003.

PATERNOSTRO, Vera Íris. O Texto na TV: manual de telejornalismo. 9. ed. Rio de Janeiro: Campus, 1999.

PENAFRIA, Manuela. O Filme Documentário: História, Identidade, Tecnologia. Lisboa: Edições Cosmos, 1999.

Universidade da Beira Interior, 1999.

Perspectivas de Desenvolvimento para o Documentarismo.

RUDIN, Richard. Introdução ao Jornalismo: técnicas essenciais e conhecimentos básicos. São Paulo: Roca, 2008.

SIQUEIRA, Fabiana Cardoso de. O Telejornalismo em Transformação: os formatos da notícia na era digital. In Porcelo, Flavio (org). O Brasil é (Ditado). Florianópolis: Insular, 2012.

STAM, Robert. Bakhtin, da Teoria Literária à Cultura de Massa. São Paulo: Ática, 2000.

VILLELA, Regina. Profissão: Jornalista de TV, Telejornalismo aplicado na Era Digital. Rio de Janeiro: Ed. Ciência Moderna, 2008.

XAVIER, Ismail (orgs.). A Experiência do Cinema: Antologia. Rio de Janeiro: Edições Graal, Embrafilme, 1983. 